\title{
Cardiac structure/function relationships: Reality or deduction?
}

Gerald Buckberg, MD See related article on page
10 .

From the Department of Cardiothoracic Surgery, David Geffen School of Medicine at UCLA, Los Angeles, Calif.

Received for publication Oct 15, 2007; accepted for publication Oct 21, 2007.

Address for reprints: Gerald Buckberg, MD, Department of Cardiothoracic Surgery, David Geffen School of Medicine at UCLA, 10833 Le Conte Ave, 62-248 CHS, Los Angeles, CA 90095-1741 (E-mail: gbuckberg@mednet.ucla.edu).

J Thorac Cardiovasc Surg 2008;136:19-20 0022-5223/\$34.00

Copyright $\odot 2008$ by The American Association for Thoracic Surgery

doi:10.1016/j.jtcvs.2007.10.086

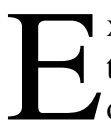
xperimental results, rather than deductions, become the final arbiter of scientific questions. To be useful, any anatomic description of the heart must address the well-documented in vivo movements structure that explains observed function because anatomic observations alone are of little value if they ignore the normal heart's coordinated and repetitive sequential motion.

Achievement of this objective requires building on prior contributions, and Anderson and colleagues have helped enormously in supplementing the landmark contributions of prior anatomists by (1) confirming the recognized clockwise and counterclockwise muscle formation with a transverse band at the base of the heart ${ }^{2}$; (2) demonstrating the collagen network housing that surrounds reciprocal helical fibers in Lunkenheimer's studies, ${ }^{3}$ which endorse the collagen weave network suggested by Grant ${ }^{4}$ in 1965; (3) corroborating Grant's observation suggesting the networking of fibers with angulated connections of myocytes to each other, ${ }^{4}$ a finding that provides structure to explain the sequential twisting motion; and (5) identifying a 100-ms prolongation of contraction in the outer oblique fibers, ${ }^{5}$ which supports the sequential contraction of the ascending segment of the apical loop defined by Torrent-Guasp ${ }^{6}$ but simultaneously disputes their synchronous contraction concept. ${ }^{5}$ Their statement that the heart is made up of millions of individual myocytes set in axially coupled endless chains in a preferential direction conveying a "grain" pattern might be correct but offers a potentially impossible solution to solving the structure/function relationship. These isolated individual observations are pieces of a puzzle that Torrent-Guasp has unraveled, as shown in our accompanying manuscript. ${ }^{1}$

The limitations of Anderson's current and prior ${ }^{7}$ functional analysis is evident by watching the working heart, the interconnected cardiac muscle fibers of which contract sequentially rather than synchronously, a distinction that is easily made by comparing regular movement with the apex and base twisting in different directions during sinus rhythm with the uniform global contraction that exists during atrioventricular pacing.

Anderson's repeated request to define an anatomic plane for different pathways ${ }^{8}$ is now evident ${ }^{1}$ from the living moving septum studies that introduce functional evidence of a reciprocal fiber structure that contracts on either side of the desired plane in a helical configuration. Therein lies the experimental evidence of the structure/function correlation. Furthermore, fixed tissue studies can introduce artifacts that are absent in the functioning heart.

Anderson and his colleagues' lifetime experience must be judged by the ultimate goal of explaining the function of the living, pumping heart, a goal that the Torrent-Guasp helical myocardial band clearly accomplishes. Scientific balance is certified by reproducible data, and the 500-year delay of recognition of Galileo should not be forgotten because he had an answer and not a deduction. The simplicity of the discovery of Torrent-Guasp revolutionized my understanding of the structure/ function relationships, and I believe that his contributions will equal or exceed those of William Harvey in fostering a dramatic expansion of our knowledge of the circulation. 


\section{References}

1. Buckberg GD, Mahajan A, Saleh S, Hoffman JIE, Coghlan C. Structure function relationships of the helical ventricular myocardial band. European J of Cardio Thoracic Surg. 2006;suppl 1:817-8.

2. Robb JS, Robb RC. The normal heart: anatomy and physiology of the structural units. Am Heart J. 1942;23:455-67.

3. Lunkenheimer PP, Muller RP, Konermann Chr, Lunkenheimer A, Kohler P. Architecture of the myocardium in computer-tomography. Invest Radiol. 1984;19:271-8.

4. Grant RP. Notes on the muscular architecture of the left ventricle. Circulation. 1965;32:301-8.
5. Lunkenheimer PP, Redmann K, Florek J, Fassnacht U, Cryer CW, Wubbeling F, et al. The forces generated within the musculature of the left ventricular wall. Heart. 2004;90:200-7.

6. Buckberg GD, Castella M, Gharib M, Saleh S. Structure/function interface with sequential shortening of basal and apical components of the myocardial band. Eur J Cardiothorac Surg. 2006;29(suppl 1):S75-97.

7. Anderson RH, Siew YH, Sanchez-Quintana D, Redmann K, Lunkenheimer PP. Heuristic problems in defining the three-dimensional arrangement of the ventricular myocytes. Anat Rec. 2006;288A:579-86.

8. Anderson RH, Sanchez-Quintana D, Redmann K, Lunkenheimer PP. How are the myocytes aggregated so as to make up the ventricular mass? Semin Thorac Cardiovasc Surg Pediatr Card Surg Annu. 2007;10:76-86. 